\title{
CARACTERÍSTICAS DE CRISTAIS DE GELO OBSERVADOS EM UM SISTEMA DE NUVENS NA AMAZÔNIA DURANTE O EXPERIMENTO TRMM-LBA
}

\author{
ALEXANDRE ARAUJO COSTA ${ }^{1}$, MUCIO COSTA CAMPOS FILHO ${ }^{2}$, ANTONIO CARLOS SANTANA \\ DOS SANTOS ${ }^{1}$, JOSÉ CARLOS PARENTE DE OLIVEIRA ${ }^{2}$
}

\author{
${ }^{1}$ Universidade Estadual do Ceará (UECE), Fortaleza, Ceará, Brasil \\ ${ }^{2}$ Instituto Federal de Educação, Ciência e Tecnologia do Ceará (IFCE), Fortaleza, Ceará, Brasil \\ alexandrearaujoc@gmail.com,mucio@ifce.edu.br,dr.acss@gmail.com, parente@fisica.ufc.br
}

Recebido Março de 2010 - Aceito Novembro de 2011

\begin{abstract}
RESUMO
Durante os meses de janeiro e fevereiro de 1999 foi realizada a campanha do TRMM/LBA (Tropical Rainfall Measuring Mission/Large Scale Biosphere-Atmosphere Experiment in Amazonia), na qual foram investigadas propriedades microfísicas de nuvens convectivas profundas. Este experimento fez parte de um esforço internacional para calibrar os equipamentos, no satélite TRMM, com o objetivo de estudar processos físicos tais como precipitação, radiação e eletricidade atmosférica. Os dados utilizados neste trabalho foram obtidos por instrumentos instalados na aeronave Citation II pertencente à Universidade de Dakota do Norte, USA, que incluem um conjunto de sondas espectrométricas, as quais medem a concentração e tamanho de partículas de gelo e de água, com destaque para a sonda bidimensional 2DC (Two-dimensional Cloud probe). Esta sonda identifica não apenas concentração e tamanho dos hidrometeoros, mas também as diferentes formas dos cristais de gelo. A aeronave realizou diversos vôos no experimento TRMM/LBA, sendo escolhido para análise o dia 10 de fevereiro de 1999. Foram observados cristais de gelo com uma grande variedade de formas e dimensões. Verificou-se certa concordância entre a forma dos cristais e os padrões de temperatura e umidade presente no ambiente, assim como foram observadas superposições de hábitos de cristais, sugerindo a existência de mistura entre diferentes regiões das nuvens e indicando que a sedimentação dos cristais pode ter grande importância para a evolução das propriedades microfísicas de nuvens convectivas profundas. Foi observado que a distribuição de tamanho dos cristais de gelo em função do diâmetro segue uma lei de potência. Palavras-chave: TRMM-LBA, convecção profunda, microfísica de nuvens, cristais de gelo
\end{abstract}

\begin{abstract}
CHARACTERISTICS OF ICE CRYSTALS OBSERVED IN A CLOUD SYSTEM OVER THE AMAZON DURING THE TRMM-LBA EXPERIMENT

During the months of January and February 1999, the TRMM/LBA (Tropical Rainfall Measuring Mission/Large Scale Biosphere-Atmosphere Experiment in Amazonia) campaign took place, in which microphysical properties of deep convective clouds were investigated. The experiment was part of an international effort to calibrate TRMM satellite sensors for precipitation, radiation and atmospheric electricity studies. The data used in the present work were collected by instruments on board North Dakota University's Citation II aircraft, including data from a set of spectrometric probes that measured concentration and size of ice crystals, with distinction to the 2DC (Two-dimensional Cloud) probe. This instrument identifies not only number concentration and size of the cloud particles, but also their shape. The aircraft performed several flights during the TRMM/LBA experiment and data from 10 February 1999 are analyzed in this paper. Inside the cloud system, ice crystals were observed in a variety of shapes and sizes. A certain agreement was found between the crystal shape and the expected patterns of ice crystal growth as a function of temperature and humidity, but crystal habit superposition was also found, suggesting the existence of mixture between air parcels from different cloud regions and indicating that crystal sedimentation plays a significant role in the evolution of the microphysics of deep convective clouds. It was also noted that the size distribution of the ice crystals follows approximately a power law.
\end{abstract}

Keywords: TRMM-LBA, deep convection, cloud microphysics, ice crystals 


\section{INTRODUÇÃO}

Incertezas relativas ao efeito das nuvens sobre o clima e da influência antropogênica sobre suas propriedades (efeito indireto dos aerossóis) são reconhecidas como sendo cruciais para os cenários de mudanças climáticas. Baker e Peter (2008) apontam que os mecanismos da contribuição antropogênica para a mudança no clima, através do efeito indireto dos aerossóis, são qualitativamente bem compreendidos. No entanto, a ausência de uma quantificação mais precisa desse efeito em escala global impõe limitações bastante significativas em sua modelagem. Segundo o próprio Painel Intergovernamental sobre Mudança Climática (Intergovernmental Panel on Climate Change, IPCC, Forster et al., 2007), o forçante radiativo atribuído ao efeito indireto dos aerossóis é de resfriamento, a uma taxa de $-0,70$ W. $\mathrm{m}^{-2}$.

A incerteza nessa estimativa, porém, é avaliada como várias vezes maior do que aquela referente ao forçante radiativo associado aos Gases de Efeito Estufa (GEEs). Ainda segundo o IPCC (Forster et al., 2007), a faixa de valores do forçante radiativo, devido ao efeito indireto dos aerossóis $(-1,80$ a - 0,30 $\left.\mathrm{W} . \mathrm{m}^{-2}\right)$, é de tal maneira ampla que não se pode descartar nem que os mesmos possam ter um efeito global bastante pequeno, nem que eles possam responder por uma compensação significativa dos efeitos dos GEEs. Segundo Costa e Pauliquevis (2009), apesar de o nível de compreensão científico acerca dos efeitos direto e indireto dos aerossóis ter se elevado recentemente, ainda há uma carência de estudos observacionais e de modelagem de microfísica de nuvens.

Visto que hoje em dia o conhecimento limitado da microfísica de nuvens e de suas interações com o ambiente de grande escala é uma das maiores lacunas em nosso entendimento do papel da convecção tropical num clima em modificação, há necessidade de experimentos de campo para investigar as características das nuvens e, assim, dar maior confiabilidade aos resultados previstos pelos modelos. Existem poucas e insuficientes observações microfísicas nos trópicos. Dentre estas, podemos citar observações de microfísica efetuadas durante o experimento TOGA COARE (Tropical Ocean Global Atmosphere Coupled Ocean Atmosphere Response Experiment, Takahashi et al., 1995), medidas de nuvens cúmulos-nimbos durante o STEP (Stratosphere-Troposphere Exchange Project, Knollenberg et al., 1993) e os dados microfísicos coletados durante o CEPEX (Central Equatorial Pacific Experiment, Chen et al., 1997). Estas observações, geralmente, revelaram peculiaridades na evolução microfísica das nuvens convectivas tropicais, algumas delas sugerindo a existência de grandes concentrações de cristais de gelo. Sobre a América do Sul, destacam-se os dados coletados nas seguintes campanhas: o Experimento do Ceará em 1994 (Costa et al., 2000), o LBA-
TRMM (Large-Scale Biosphere-Atmosphere Experiment in Amazonia - Tropical Rainfall Measuring Mission, Stith et al., 2002, Heymsfield et al., 2002) e o LBA-SMOCC-EMfiN! (Large-Scale Biosphere-Atmosphere Experiment in AmazoniaSmoke Aerosols, Clouds, Rainfall and Climate-Experimento de Microfisica de Nuvens, Andreae at al., 2004; Freud et al., 2008; Martins et al., 2009; Costa e Pauliquevis, 2009).

Em particular, os experimentos realizados sobre a Amazônia revelam um contraste bastante evidenciado entre as condições limpas da estação chuvosa e as condições extremamente poluídas no período das queimadas (Kaufman et al., 1998, Artaxo et al., 1998, Rosenfeld, 1999, Sherwood, 2002, Artaxo et al., 2002, Andreae at al., 2004, Freud et al., 2008, Martins et al., 2009; Costa e Pauliquevis, 2009), daí ser necessário, com vistas a uma representação apropriada da convecção sobre a região, mapear seu ciclo anual.

Outro aspecto importante a ser considerado é que modelos atmosféricos mais modernos requerem informações que não se restringem à concentração de partículas, mas para as quais a forma da distribuição de tamanhos é importante (e.g., Ferrier, 1994, Walko et al., 1995, Meyers et al., 1997, Liu et al., 2007, Xie e Liu, 2009).

No presente trabalho, pretendemos descrever as características da microfísica de fase sólida nos sistemas precipitantes na Amazônia durante o experimento TRMM-LBA, tais como: concentração e diâmetro médio de hidrometeoros ("graupel" e cristais de gelo), distribuição de hidrometeoros por tamanho, conteúdos de água líquida e sólida, ocorrência de diferentes formas de cristais de gelo, etc. É fácil perceber que, em nuvens convectivas profundas, cujo topo pode ser encontrado até nas proximidades da tropopausa, entre 16 e $20 \mathrm{~km}$ nos trópicos (muito acima do nível de congelamento, que está entre 4 e $5 \mathrm{~km}$ nessas regiões), a fase de gelo adquire grande importância. Em nuvens do tipo cúmulos-nimbos, grande parte do material condensado encontra-se, na verdade, em fase sólida.

O artigo está organizado como segue: a seção 2 contém uma descrição do experimento TRMM-LBA, destacando a instrumentação utilizada nos estudos microfísicos e a metodologia do experimento. Na seção 3, são analisados os dados obtidos referentes à fase de gelo no sistema observado em 10 de fevereiro de 1999. Por último, os resultados obtidos são discutidos, bem como são apresentadas sugestões para futuros trabalhos.

\section{DADOS E METODOLOGIA}

Um grande experimento de campo se realizou no Estado de Rondônia, entre novembro de 1998 e fevereiro de 1999 e parte dele compôs o programa de validação na superfície dos dados amostrados remotamente pelo TRMM. A busca de 
um melhor entendimento das características da precipitação, a melhoria das técnicas de medidas diretas e estimativas da precipitação, por métodos remotos e a validação de produtos derivados de satélite, estavam entre os objetivos científicos principais deste programa.

O experimento teve início em 01 de novembro de 1998, com medidas de radares (S-pol, banda S e TOGA, banda C), medidas extensivas com pluviômetros e sondagens com balões cativos e balões meteorológicos.

Nos meses de janeiro e fevereiro, dois aviões juntaram-se ao experimento. O primeiro avião foi o ER-2 da NASA, que voou a cerca de $20 \mathrm{~km}$ de altura e que continha alguns sensores semelhantes aos do satélite TRMM. Assim, ele amostrou nos seus voos dados semelhantes aos que o TRMM amostrou de sua órbita. O outro avião foi o jato Cessna Citation II da Universidade Dakota do Norte, que coletou os dados analisados no presente artigo. Por ser um jato pressurizado, com teto de operação de aproximadamente $13 \mathrm{~km}$, a aeronave era adequada para estudos em nuvens frias e de fase mista, podendo amostrar torres convectivas profundas e nuvens de bigorna. Este avião abrigava o seguinte conjunto de equipamentos para microfísica de nuvens: a) Particle Measuring System FSSP-100 (Forward Scattering Spectrometer Probe, Sonda Espectrométrica de Pró-Espalhamento, para partículas de 4 a $52 \mu \mathrm{m}$ ), baseada em espalhamento Mie de luz laser por gotículas e cujo funcionamento é descrito, dentre outros trabalhos, em Pinnick et al. (1981), Dye e Baumgardner (1984) e Baumgardner et al. (1985); b) 2D-C (Two-dimensional Cloud probe, Sonda de Nuvens Bidimensional, para partículas de 81 a $956 \mu \mathrm{m})$ e 2D-P (Two-dimensional Precipitation probe, Sonda de Precipitação Bidimensional, para partículas de $400 \mu \mathrm{m}$ a $3 \mathrm{~mm}$ ), baseadas no sombreamento de um feixe de laser por hidrometeoros, cujo princípio de funcionamento e uso são discutidos, dentre outros, por Knollenberg (1970), Heymsfield e Baumgardner (1985) e Korolev et al. (1991); c) CPI (Cloud Particle Imager, Imageador de Partículas de Nuvens; que apresenta resolução de imagem muito superior ao das sondas ópticas, conforme apontado por Unalowsky et al., 2004 e Connolly et al., 2007; que descrevem este equipamento em detalhes) e d) HVPS (High Volume Particle Spectrometer, Espectrômetro de Partículas de Grande Volume, para partículas de algumas centenas de micrometros a alguns milímetros), cuja descrição é feita por Lawson et al. (1993).

Durante a campanha, o Citation realizou diversos vôos, sendo que alguns foram mais dedicados a estudos da fase quente, outros investigaram prioritariamente a banda brilhante, etc. Especificamente nos dias 10 e 17 de fevereiro de 1999, a aeronave amostrou hidrometeoros em sistemas convectivos maduros, com medidas em múltiplos níveis. $\mathrm{O}$ caso de 10 de fevereiro foi analisado neste artigo, considerando que este foi um dos dois vôos em que medidas de hidrometeoros de fase sólida em diferentes níveis foram obtidas em um sistema convectivo organizado.

\section{RESULTADOS}

\subsection{Estudo de caso de 10 de fevereiro de 1999}

No dia 10 de fevereiro de 1999, no horário de 1500 UTC, havia condições meteorológicas propícias à formação de grandes células convectivas organizadas, visto que, pela análise do perfil vertical da atmosfera através do $S k e w-T$, mostrado na Figura 1, observa- se um valor relativamente alto da energia potencial convectiva $(1727 \mathrm{~J} / \mathrm{kg})$ e uma baixa energia de inibição convectiva $(13 \mathrm{~J} / \mathrm{kg})$. O nível de condensação por levantamento localizava-se em torno de 900 $\mathrm{hPa}$ (cerca de $950 \mathrm{~m}$ de altitude), e o nível de congelamento em aproximadamente $600 \mathrm{hPa}$ (ou cerca de $4800 \mathrm{~m}$ ). O nível de equilíbrio se encontrava em torno de $150 \mathrm{hPa}$ (acima de 14 $\mathrm{km}$ ). De acordo com Adams et al. (2009), um valor de CAPE acima de $1500 \mathrm{~J} / \mathrm{kg}$ é compatível com o chamado "regime de leste" (como no caso de 10 de fevereiro de 1999, cujos ventos são também indicados na Figura 1, com predomínio de ventos de leste na baixa troposfera), caracterizado geralmente por linhas de instabilidade propagantes - sistemas mais intensos do que o observado para o "regime de oeste".

Aproximadamente neste nível se verificou o encontro das curvas de temperatura do ponto de orvalho e temperatura ambiente e uma acentuada declividade na curva da temperatura do ponto de orvalho, provocada pelo decréscimo da umidade em prol do aumento da fase sólida. Por último, o nível de equilíbrio estava em torno de $150 \mathrm{hPa}$ (acima de $14 \mathrm{~km}$ ), valor aproximado da altura de topo das nuvens.

$\mathrm{O}$ vôo foi realizado em um sistema convectivo, no intervalo entre 1740 e 2010 UTC. Inicialmente a uma altitude de $7,6 \mathrm{~km}$, a aeronave amostrou os primeiros cristais de gelo em 1805 UTC, logo após subindo ao nível de 8,8 km. Neste nível, a penetração no sistema se fez em uma linha reta de aproximadamente $100 \mathrm{~km}$ de extensão na direção Noroeste entre 1820 e 1840 UTC. O avião retornou ao nível de 7,6 km e penetrou no sistema de nuvens duas vezes entre os tempos 1845 e 1915 UTC, em uma trajetória aproximadamente linear. Depois disso, descreveu uma trajetória com duas voltas do tipo nó de gravata, com cerca de $10 \mathrm{~km}$ de comprimento, a primeira entre 1915 e 1925 UTC e a segunda entre 1945 e 1953 UTC. Finalmente, o avião percorreu uma espiral descendente até o nível de $5,5 \mathrm{~km}$. A trajetória do avião projetada no plano (com indicação da posição da aeronave em diversos horários) e a imagem de radar da linha de instabilidade estudada no instante 1829 UTC são mostradas nas Figuras 2 e 3, respectivamente. 


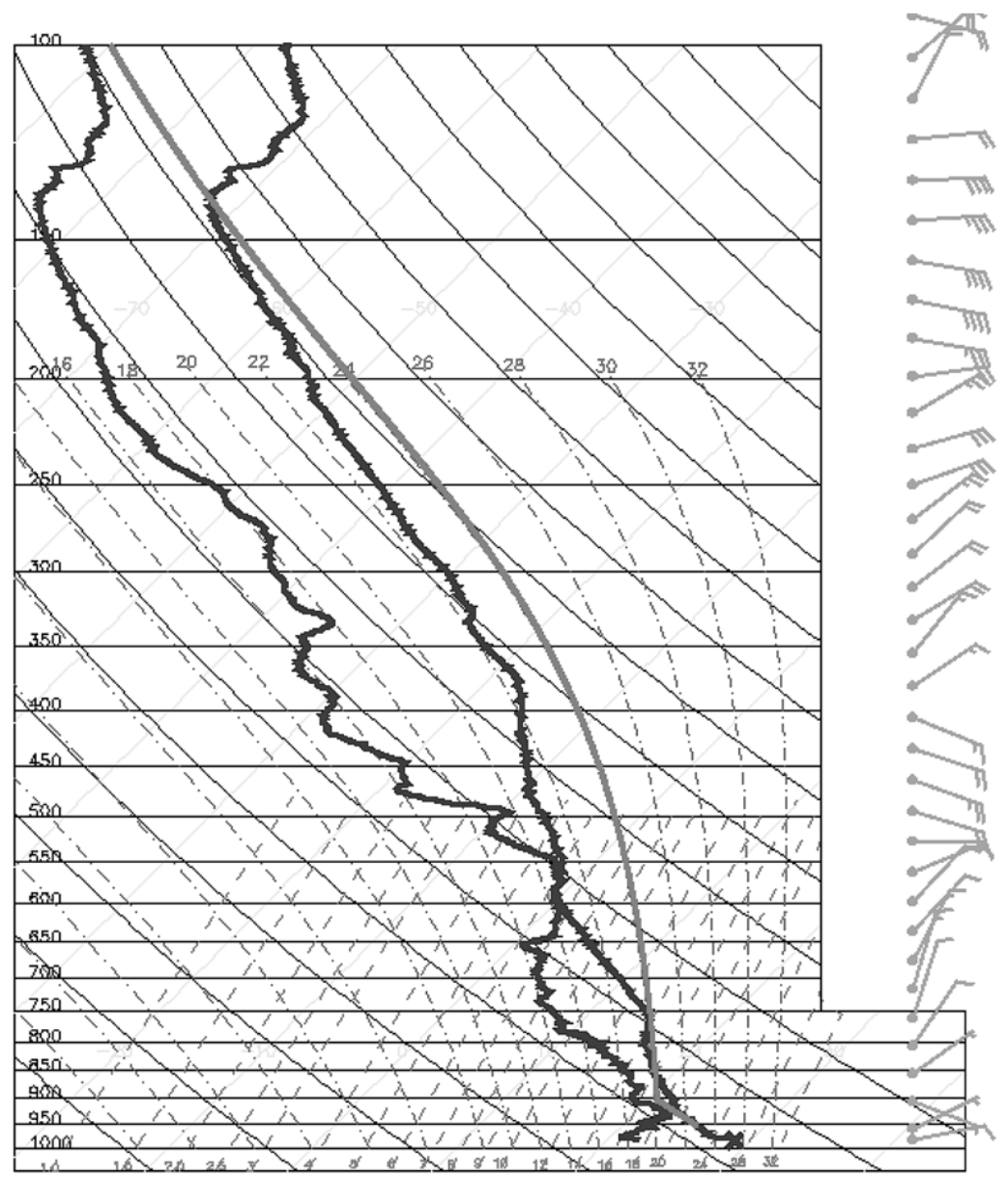

Figura 1 - Diagrama SkewT do dia 10 de fevereiro de 1999, às 1200 UTC, na região do experimento TRMM/LBA.

Conforme se aproximou da linha de instabilidade, no nível de 7,6 km, o avião passou paralelamente ao sistema de nuvens, à frente da convecção ativa. O Citation voou através de uma região relativamente seca, sem movimento vertical significativo, encontrando concentrações relativamente pequenas de cristais de gelo, em 1806 UTC. Os cristais eram em sua maioria planares, com algumas partículas grandes, do tipo estelar/dendrítico e agregados. A Figura 4 mostra temperatura, velocidade vertical, concentração de partículas medidas pelas sondas FSSP, 2DC e 1DP, umidade relativa, supersaturação em relação ao gelo, diâmetro médio medido pelas três sondas citadas e algumas imagens de 2DC. O hábito dominante (planar) concorda com o intervalo de temperatura de $-17 \mathrm{a}-19^{\circ} \mathrm{C}$.

A passagem seguinte foi dentro do sistema convectivo, na altitude de $8,8 \mathrm{~km}$. A maioria dessas regiões mostrou-se saturada em relação à água e, em conseqüência, supersaturadas em relação ao gelo. O tipo de hidrometeoro dominante foi o de cristais de forma irregular, tais como partículas de graupel, e pequenos cristais colunares, particularmente na porção sul do sistema. O hábito colunar concorda com o intervalo de temperatura de -27 a $-30{ }^{\circ} \mathrm{C}$ observado na nuvem e com o suprimento significativo de vapor de água.

Outras formas de cristais também foram encontradas, tais como rosetas, projéteis e cristais planares. Ventos ascendentes de baixa intensidade foram observados (velocidades verticais inferiores a $6 \mathrm{~m} / \mathrm{s}$ ), com concentrações de FSSP, 2DC e 1DP maiores que $10 \mathrm{~cm}^{-3}, 200 l^{-1}$ e $20 l^{-1}$, respectivamente. Especialmente na porção norte do sistema, as partículas amostradas pela FSSP foram pequenas (diâmetro médio da ordem de $10 \mu \mathrm{m}$ ). A Figura 5 mostra variáveis dinâmicas, termodinâmicas e microfísicas, bem como as imagens de cristais de gelo em certas regiões do sistema (amostradas entre 1831 e 1837 UTC), que exemplificaram bem essas características.

Depois de atravessar o sistema de nuvens no nível de $8,8 \mathrm{~km}$, o Citation II desceu novamente para o nível de 7,6 $\mathrm{km}$, onde duas penetrações em linha reta foram realizadas. Durante as penetrações, a umidade relativa ficou na ordem de $80 \%$ na maioria das regiões, o que significa saturação ou ligeira subsaturação com respeito ao gelo. 


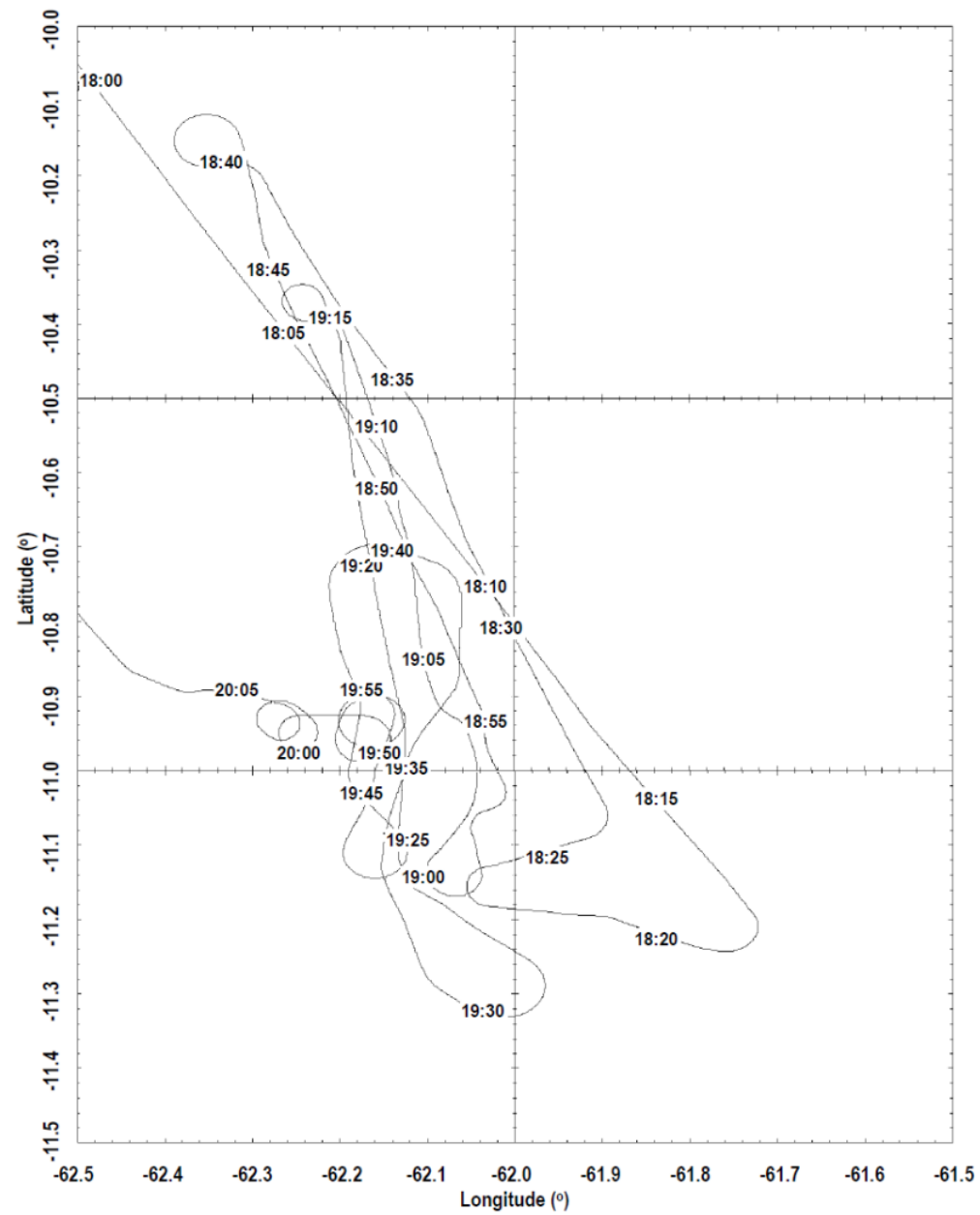

Figura 2 - Trajetória do avião Citation entre 1800 e 2010 UTC em 10 de fevereiro 1999. O tempo está indicado em intervalo de 5 min.

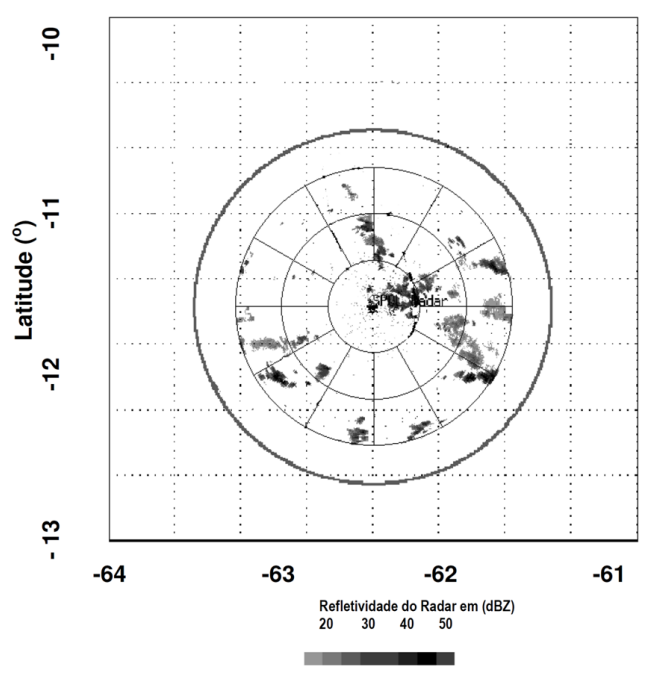

Figura 3 - Imagem do radar S-Pol mostrando o sistema convectivo observado durante o experimento TRMM/LBA em 10 de fevereiro de 1999, às 1829 UTC. A refletividade do radar, em dBZ, é representada na escala de cinza.
Este padrão apresentava fortes descontinuidades associadas à presença de fortes ascendentes, chegando às vezes a exceder os $10 \mathrm{~m} / \mathrm{s}$ (incluindo uma célula muito intensa, que foi penetrada duas vezes pelo avião, e em que o movimento vertical alcançou $20 \mathrm{~m} / \mathrm{s}$ ). Estes ascendentes eram mais quentes do que sua vizinhança, chegando a saturar (ou supersaturar) com respeito a água. A localização das maiores velocidades verticais e das máximas concentrações de partículas (detectadas particularmente pela FSSP) geralmente coincidia.

As regiões menos ativas foram caracterizados por hábitos dos cristais similares aos encontrados durante a primeira passagem no mesmo nível, isto é, cristais planares, muitos deles com extensões dendríticas, e agregados destes cristais. Nas regiões mais ativas, entretanto, partículas de graupel foram dominantes. A alta concentração de hidrometeoros e supersaturação do ambiente com respeito a água pode sugerir que o processo de encrostamento (ou riming) contribuiu fortemente para o crescimento das partículas de gelo.

A Figura 6 mostra temperatura, velocidade vertical, medidas de concentração de partículas dadas pelas FSSP, 2DC 

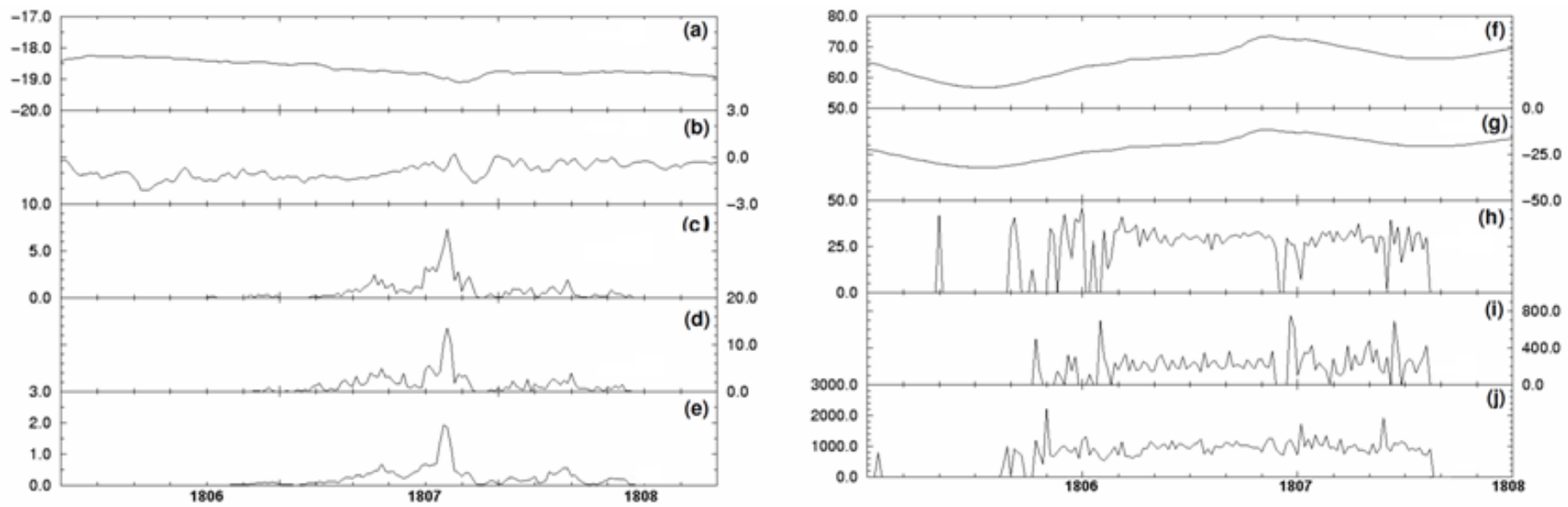

(k)

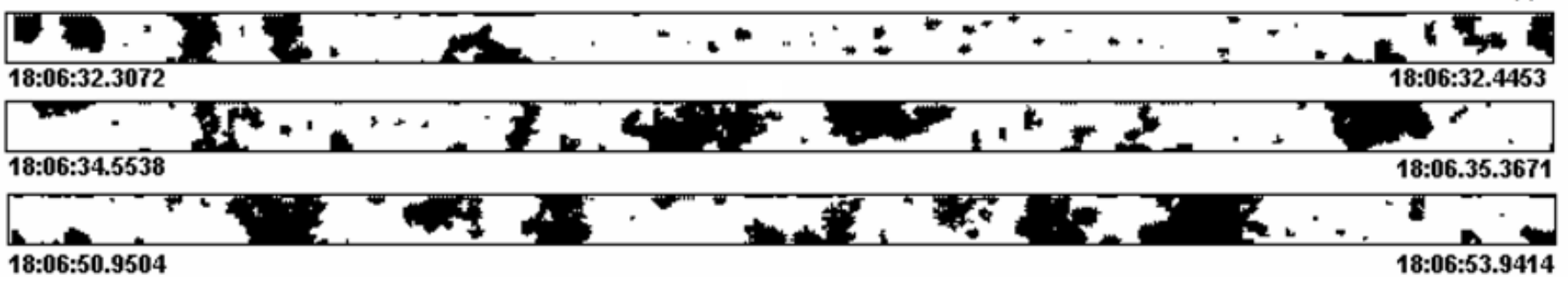

Figura 4 - (a) Temperatura, em oC, (b) Velocidade vertical, em m.s-1, (c) Concentração de FSSP, em cm-3, (d) Concentração de 2DC, em 1-1, (e) Concentração de 1DP, em 1-1, (f) Umidade Relativa, em \%, (g) Supersaturação com respeito ao gelo, em \%, (h) Diâmetro médio da FSSP, em $\mu$ m, (i) Diâmetro médio de 2DC, em $\mu \mathrm{m}$, (j) Diâmetro médio de 1DP, em $\mu \mathrm{m}$, (k) Imagens de 2DC.
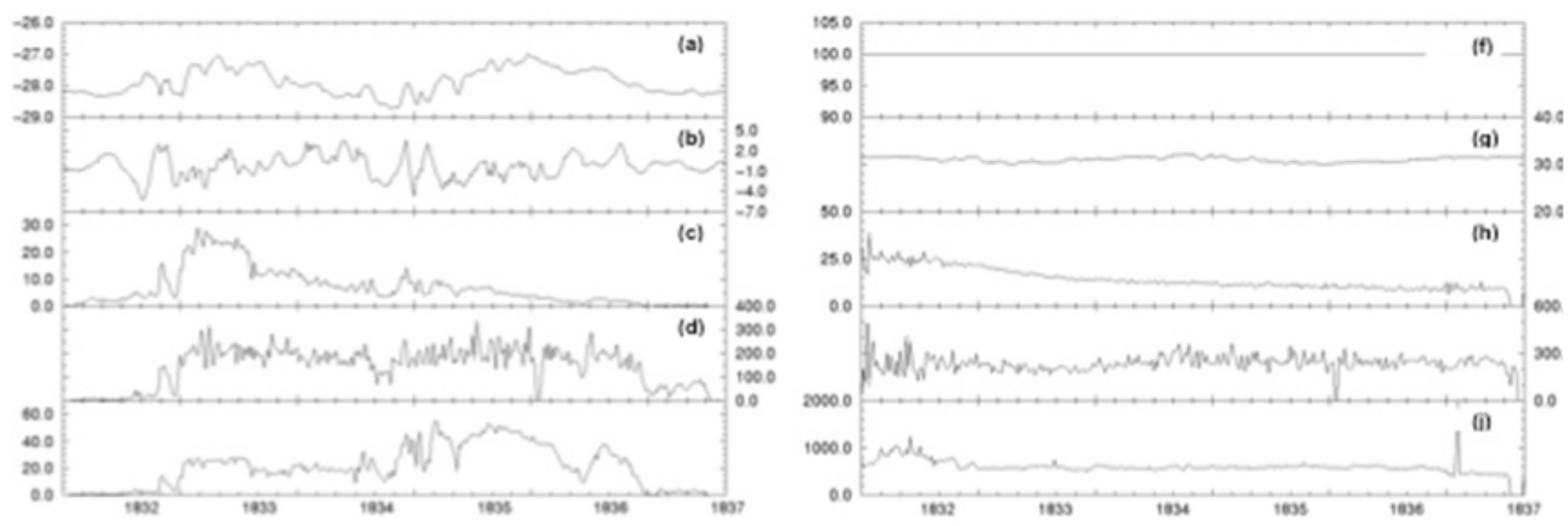

$(\mathrm{k})$

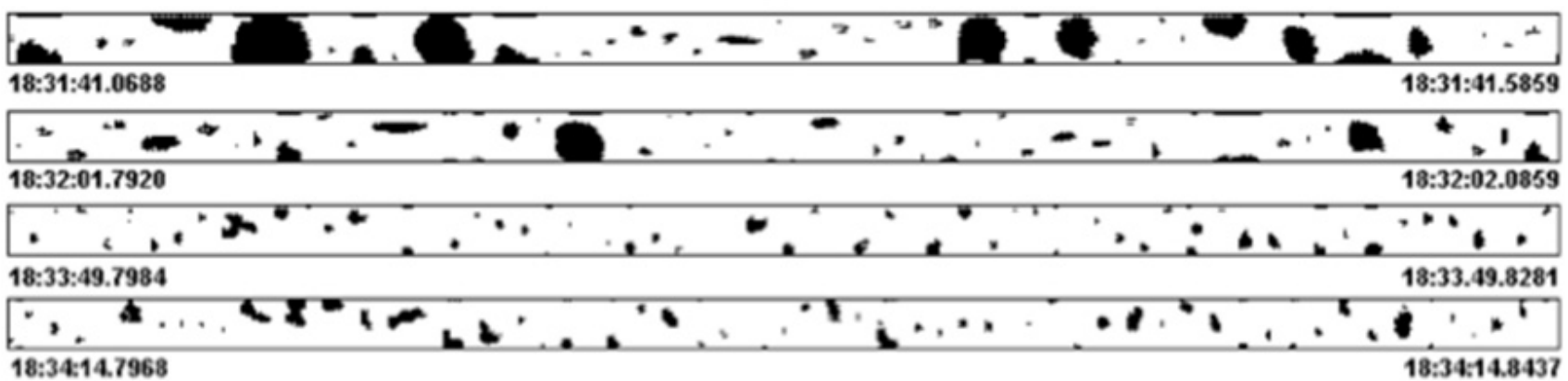

Figura 5 - Idêntica à Figura 4, mas para a segunda passagem (Trajetória em linha no nível de 8,8km). 

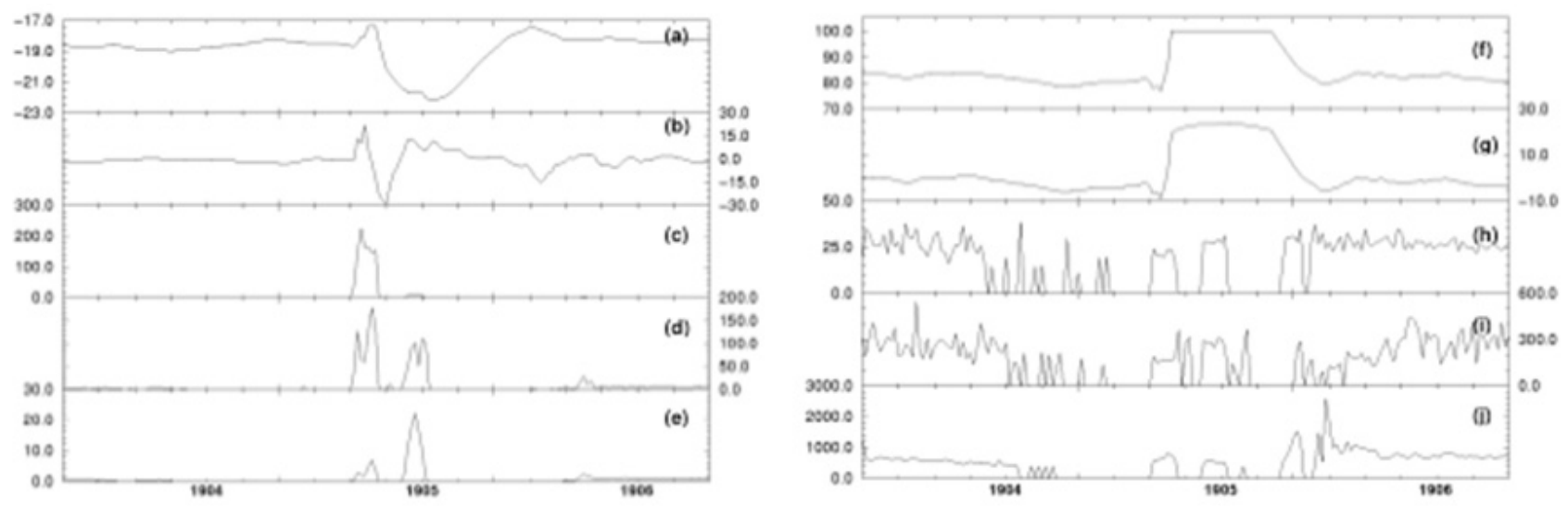

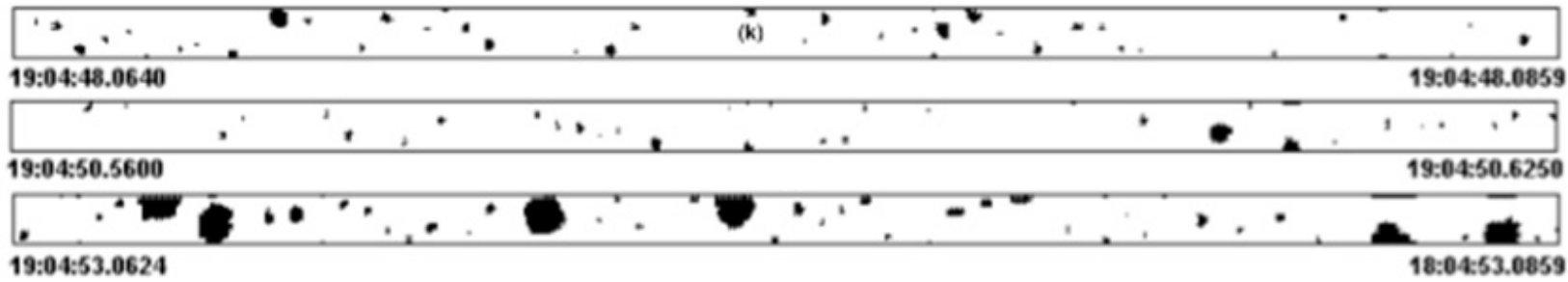

Figura 6 - Idêntica à Figura 4, mas para a terceira passagem (Duas trajetórias em linhas, em 7,6km).

e 1DP, umidade relativa, supersaturação com respeito ao gelo, diâmetro médio medido pelas três sondas e imagens de 2DC para a segunda penetração no ascendente mais forte encontrado no sistema de nuvens. Tanto a temperatura (Figura 6a) quanto a umidade relativa (Figura $6 \mathrm{f}$ ) aumentaram bruscamente, associadas com elevados valores de velocidade vertical positiva (Figura 6b). Muitas partículas estavam presentes no centro do ascendente, com concentração de FSSP excedendo a valores de $200 \mathrm{~cm}^{-3}$.

Ao mesmo tempo (aproximadamente 19:04:40 UTC), as concentrações de 2DC e 1DP foram maiores que $150 l^{-1} \mathrm{e} 20 l^{-1}$, respectivamente. Na vizinhança dessa região, as concentrações de FSSP e 2DC diminuíram, enquanto a concentração de 1DP aumentou, sugerindo uma mudança de um regime de partículas menores para outro de partículas maiores. Esta transição pode ser vista com as imagens da sonda 2DC (Figura 6k).

Mais tarde, na mesma passagem, na porção norte do sistema (caracterizada por ventos verticais moderados e diminuição acentuada do vapor disponível, ficando próximo à saturação com respeito ao gelo) um grupo de cristais do tipo CP2a e similares foi encontrado (Figura 7), indicando uma superposição de hábitos.

Aparentemente, não existiam novos cristais de gelo sendo nucleados nesta região, por este motivo os cristais planares não dominaram (o que seria esperado em temperaturas entre $-17 \mathrm{a}-18{ }^{\circ} \mathrm{C}$ ). Foram encontrados, em vez disso, vários cristais colunares, provavelmente formados em outras regiões das nuvens, com ou sem superposição do hábito planar.
Em seguida, o Citation II realizou uma trajetória do tipo nó de gravata em um nível mais alto (acima de $10 \mathrm{~km}$ ). O avião encontrou saturação/supersaturação com respeito à água em toda a extensão da passagem. A alta supersaturação com respeito ao gelo (excedendo 40\%) foi acompanhada de concentrações de fundo de $20-30 \mathrm{~cm}^{-3}$ para a FSSP, aproximadamente $200 l^{-1}$ para a $2 \mathrm{DC}$ e da ordem de $20 l^{-1}$ para a $1 \mathrm{DP}$.

$\mathrm{O}$ diâmetro médio medido pelas sondas foi também bastante uniforme (da ordem de $25 \mu \mathrm{m}$ para a FSSP, $250 \mu \mathrm{m}$ para a $2 \mathrm{DC}$ e $600 \mu \mathrm{m}$ para a 1DP). As maiores mudanças na concentração foram encontradas em um forte ascendente (o mesmo que foi penetrado na passagem anterior em linha reta). Dentro do núcleo do ascendente (velocidade vertical em torno de $20 \mathrm{~m} / \mathrm{s}$ ), a concentração de partículas medidas pela FSSP aproximou-se de valores de $150 \mathrm{~cm}^{-3}$, isto é, cinco vezes mais do que no restante daquele nível. Apesar do forte aumento na concentração de partículas medidas pela FSSP, a concentração de partículas medidas pela 1DP no ascendente foi somente duas vezes maior do que em outras regiões e a concentração de partículas medidas pela 2DC variou apenas ligeiramente.

A Figura 8 representa temperatura, velocidade vertical, concentração de partículas, umidade relativa, supersaturação com respeito ao gelo, diâmetros médios e imagens da 2DC para uma parte da quarta passagem (entre 190320 e 190820 UTC). Não foi encontrado nenhum padrão nas formas das partículas de gelo, apesar de uma mistura de pequenos cristais, na forma 


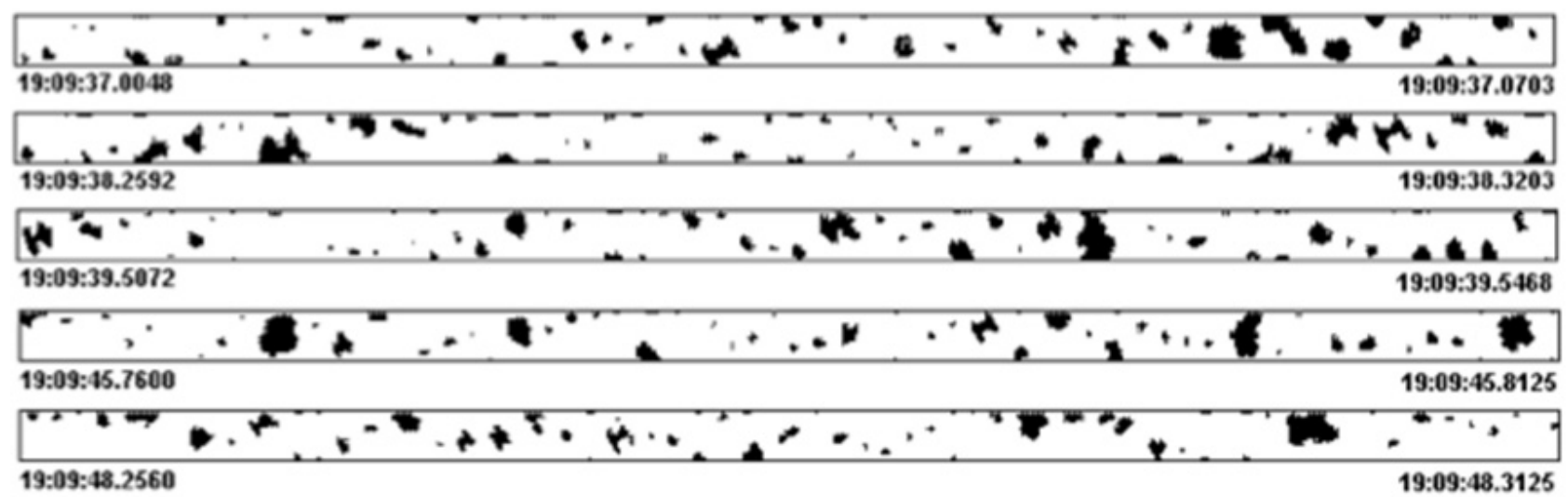

Figura 7 - Imagens da sonda 2DC coletadas na parte norte do sistema durante a terceira passagem.
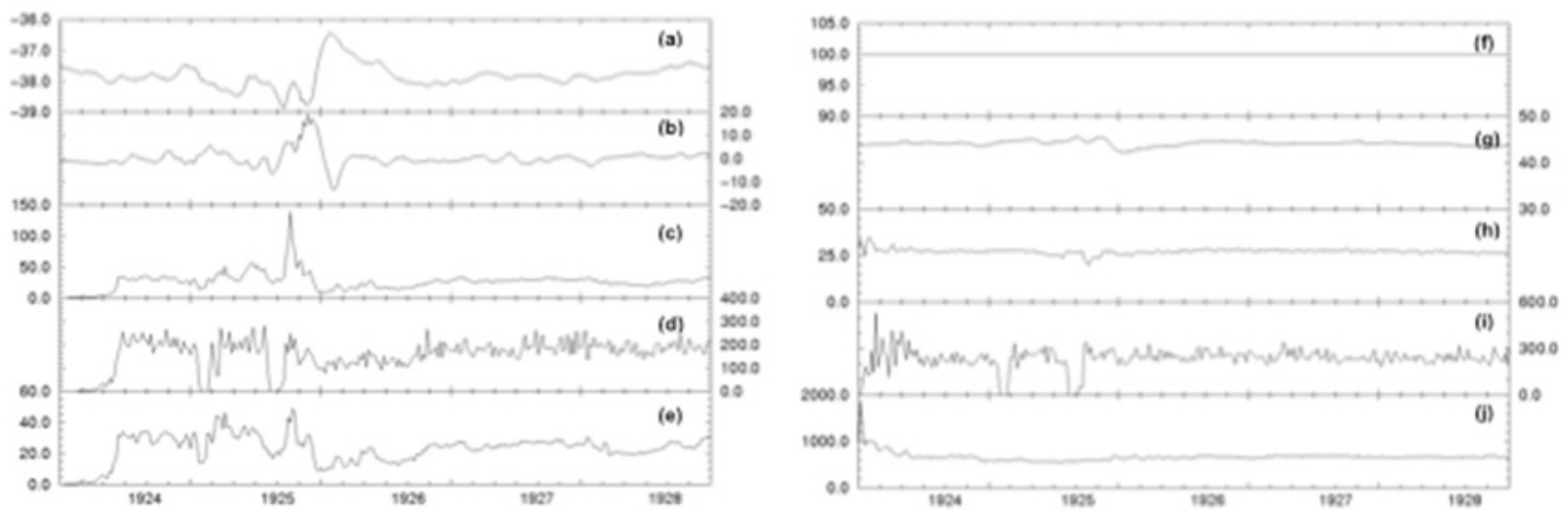

(k)

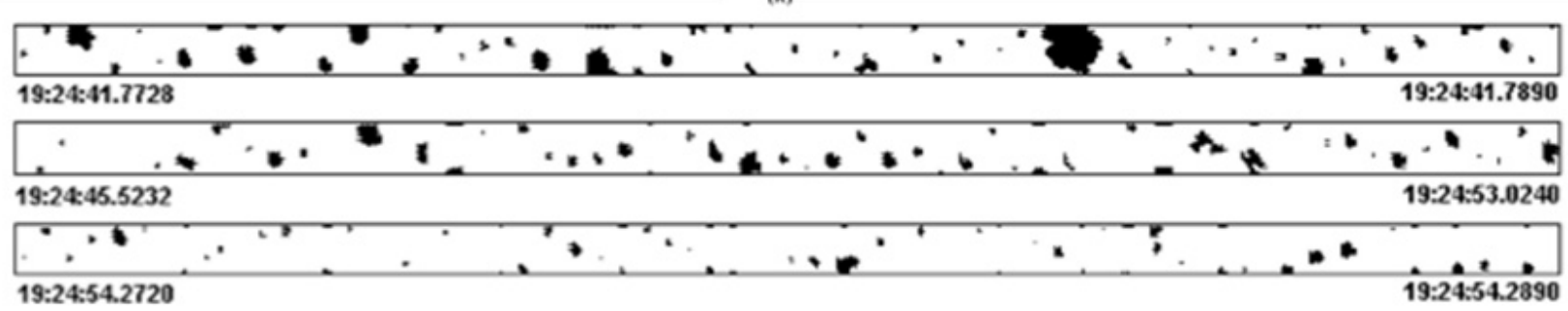

Figura 8 - Idêntica a Figura 4, mas para a quarta passagem (nó de gravata no nível de 10km).

de placas duplas e outros de formatos irregulares, ser visível na Figura 8k.

Depois que passou no nível de $10 \mathrm{~km}$, o avião retornou à altitude de aproximadamente de $8,8 \mathrm{~km}$, onde ele realizou mais uma trajetória curta do tipo "nó de gravata". Dados desta passagem são mostrados na Figura 9. O intervalo de temperatura foi entre -27 e $-29{ }^{\circ} \mathrm{C}$ (Figura 9a). A umidade relativa ultrapassou os $90 \%$, o que corresponde a supersaturações com respeito ao gelo maiores do que $20 \%$ (Figuras 9f e 9g).

As concentrações de partículas foram maiores do que $30 \mathrm{~cm}^{-3}$ (FSSP, Figura 9c), $200 l^{-1}$ (2DC, Figura 9d) e $50 l^{-1}$
(1DP, Figura 9e) e os diâmetros médios foram da ordem de 30

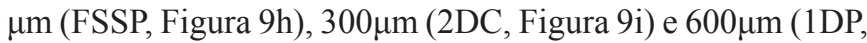
Figura 9 j). Uma variedade significativa nas formas dos cristais foi encontrada, com partículas do tipo graupel, cristais colunares e cristais planares duplos co-existindo na mesma região, tal como visto na Figura 9k.

Finalmente, o Citation II entrou numa trajetória espiral descendente, na qual colheu amostras na linha de estabilidade de $8 \mathrm{~km}$ até $5 \mathrm{~km}$ (correspondendo a um intervalo de temperatura de aproximadamente $-30^{\circ} \mathrm{C} \mathrm{a}-2^{\circ} \mathrm{C}$ ). Durante a passagem, uma variedade de hábitos de cristais de gelo foi encontrada, com uma fraca concordância entre os hábitos 

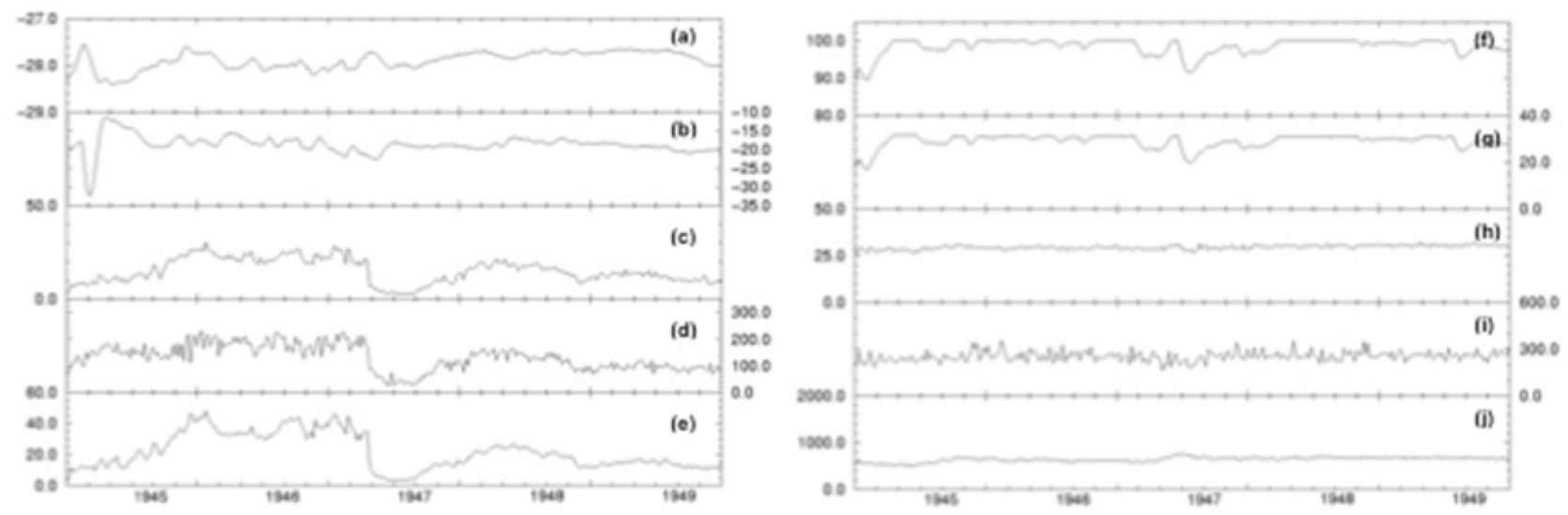

(k)

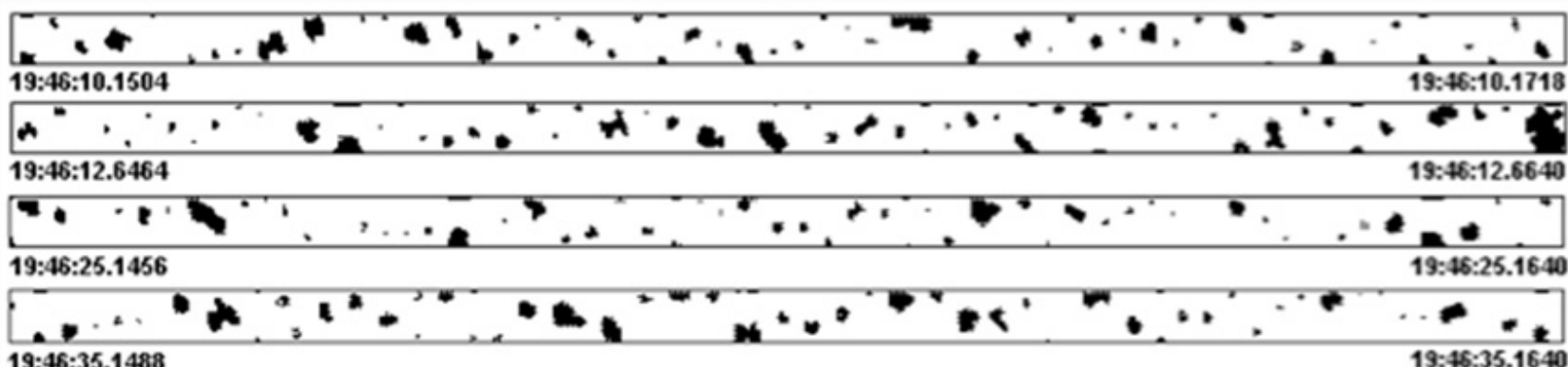

Figura 9 - Idêntica a Figura 4, mas para a quinta passagem (nó de gravata curto no nível de 8,8km).

observados e aqueles esperados em função da temperatura. A Figura 10 mostra a altitude (Figura 10a), temperatura (Figura 10b), medidas de concentração pela FSSP (Figura 10c), 2DC (Figura 10d) e 1DP (Figura 10e) bem como amostras de imagens da sonda 2DC em diferentes intervalos de temperatura (10f).

Sumarizando, apresentamos na Tabela 1 os valores médios de altitude, temperatura, concentração e diâmetros medidos por meio das sondas espectrométricas. Apesar de uma forte variabilidade dos parâmetros microfísicos (associada com a natureza não homogênea da convecção), foi observado que, com exceção da primeira passagem (na borda do sistema), as grandezas medidas, principalmente pelas sondas 2DC e 1DP, mantiveram-se quase uniformes com respeito à altura.

A Figura 11 representa as observações da concentração de FSSP (Figura 11a), 2DC (Figura 11b) e 1DP (Figura 11c) para o dia 10 de fevereiro. Valores máximos de concentração medidos por essas sondas, respectivamente acima de 20 $\mathrm{cm}^{-3}, 0,30 \mathrm{~cm}^{-3}$ e $0,50 \mathrm{~cm}^{-3}$, são visíveis em praticamente todos os níveis. Estes valores máximos, como indicado na seção anterior e mostrado nas Figuras 4-6, 8 e 9, geralmente coincidem com a posição das correntes ascendentes. É nestas que o vigoroso transporte vertical de material condensado para regiões de temperatura muito baixa deve iniciar o processo de nucleação homogênea da fase sólida, levando a grandes concentrações de cristais de gelo. É particularmente marcante o máximo de concentração medida pela FSSP (intervalo até $52 \mu \mathrm{m}$ ) verificado quando da terceira passagem no interior do sistema convectivo, que excedeu $200 \mathrm{~cm}^{-3}$. Aparentemente, a concentração máxima sofreu uma redução entre 6 e 7,6 $\mathrm{km}$, possivelmente associada com agregação de cristais de dendritos. Os valores predominantes de diâmetro médio foram da ordem de $30 \mu \mathrm{m}$ (FSSP), $300 \mu \mathrm{m}$ (2DC) e $600 \mu \mathrm{m}$ (1DP), sendo que, estes valores tiveram uma ligeira diminuição com a altura, como mostra a Figura 12.

A distribuição de tamanho de partículas maiores que 10 $\mu \mathrm{m}$ também foi uniforme em diferentes estágios do ciclo de vida da nuvem nos dois casos estudados. A Figura 13 mostra a função distribuição de hidrometeoros para as passagens 2 e 5 e a espiral descendente, bem como a melhor representação dos valores aproximados, utilizando o recurso da regressão linear. O gráfico mostra o melhor ajuste para distribuição de partículas maiores que $10 \mu \mathrm{m}$ obtida usando uma lei da potência (uma das funções sugeridas por Liu et al., 1995) na forma (Auer, 1972): Conforme Equação 1 a seguir.

$$
F(D)=a \cdot D^{b},
$$

onde $a=4745, b=-3,11, D$ é dado em $\mu \mathrm{m}, b$ é a declividade da distribuição e $a$ é o coeficiente linear. Vale ressaltar que o valor 


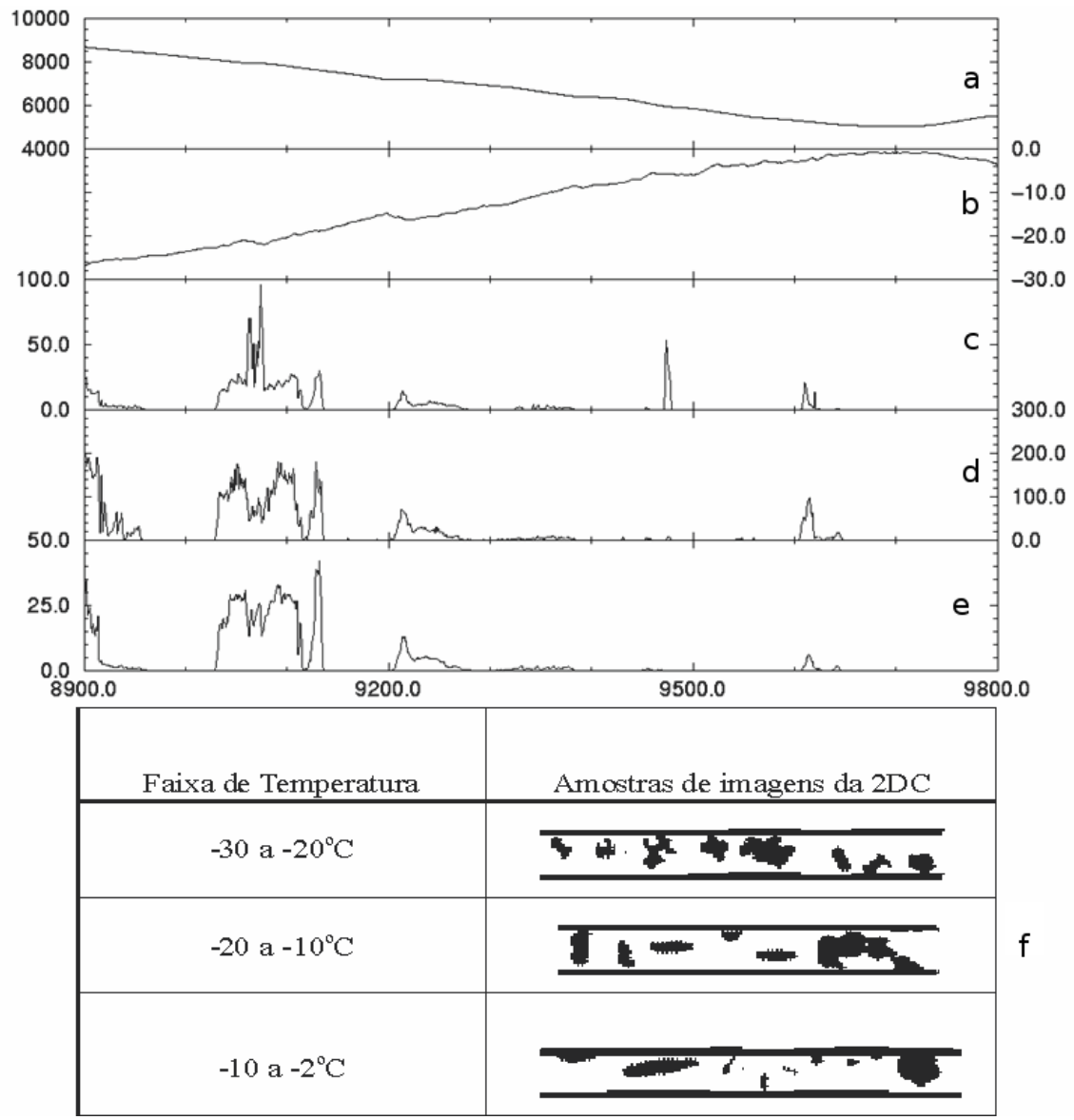

Figura 10 - Observações durante a ultima passagem (trajetória em espiral descendente de 8,8km até 4,8km) (a) Altitude em m , (b) Temperatura, em oC, (c) Concentração de partículas medidas pela FSSP, em cm-3, (d) Concentração de partículas medidas pela 2DC, em 1-1, (e) Concentrção de 1DP, em 1-1, (f) Imagens de 2DC.

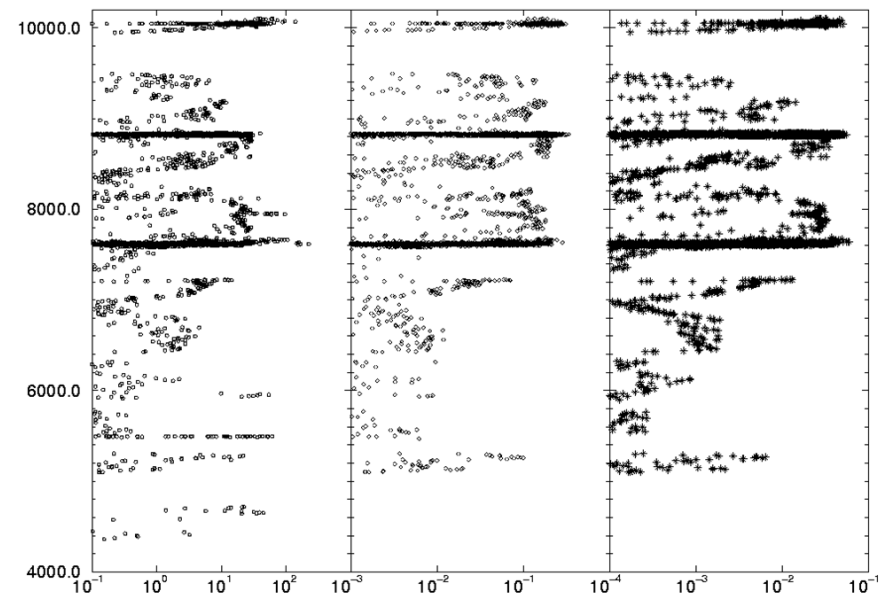

Figura 11- Concentração de partículas em cm-3, com altura: (a) FSSP, (b) $2 \mathrm{DC}$ e (c) $1 \mathrm{DP}$.

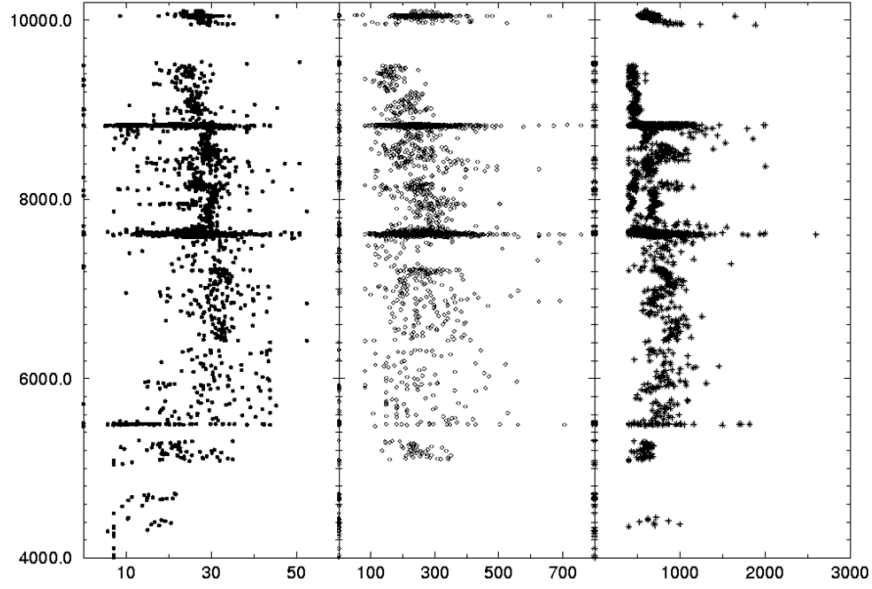

Figura 12 - Diâmetro médio em $\mu \mathrm{m}$, com altura: (a) FSSP, (b) 2DC e (c) 1DP. 
Tabela 1 - Valores médios de altitude, temperatura e grandezas microfísicas e valores máximos das concentrações por passagem da aeronave no interior do sistema convectivo. Somente trechos das passagens em que as concentrações na FSSP, 2DC e 1DP respectivamente maiores que 1,0 cm-3 1,0 1-1 e 0,1 1-1 foram consideradas no cálculo das médias das variáveis concernentes a cada sonda. Supersaturação com respeito à água é indicada apenas qualitativamente.

\begin{tabular}{|c|c|c|c|c|c|}
\hline & $\begin{array}{c}\text { Passagem } \\
1\end{array}$ & $\begin{array}{l}\text { Passagem } \\
2\end{array}$ & $\begin{array}{c}\text { Passagem } \\
3 \\
\end{array}$ & $\begin{array}{c}\text { Passagem } \\
4\end{array}$ & $\begin{array}{c}\text { Passagem } \\
5\end{array}$ \\
\hline Altitude média $(\mathrm{km})$ & 7,6 & 8,8 & 7,6 & 10,0 & 8,8 \\
\hline Temperatura média $\left({ }^{\circ} \mathrm{C}\right)$ & $-18,6$ & $-27,0$ & $-18,8$ & $-37,8$ & $-27,9$ \\
\hline $\begin{array}{l}\text { Umidade Relativa média } \\
(\%)\end{array}$ & 65,4 & $>100$ & 85,5 & $>100$ & $>100$ \\
\hline $\begin{array}{l}\text { Supersaturação média com } \\
\text { respeito ao gelo }(\%)\end{array}$ & $-21,5$ & $+32,2$ & $+2,3$ & $+23,5$ & $+44,0$ \\
\hline $\begin{array}{l}\text { Média da Concentração } \\
\left(\text { FSSP }, \mathrm{cm}^{-3}\right)\end{array}$ & 2,2 & 28,3 & 100,3 & 27,9 & 15,1 \\
\hline $\begin{array}{l}\text { Concentração Máxima } \\
\left(\mathrm{FSSP}, \mathrm{cm}^{-3}\right)\end{array}$ & 6,7 & 24,2 & 219,6 & 134,2 & 29,8 \\
\hline $\begin{array}{l}\text { Diâmetro médio (FSSP, } \\
\square \mathrm{m})\end{array}$ & 23,3 & 15,8 & 24,4 & 29,1 & 29,6 \\
\hline $\begin{array}{l}\text { Média da Concentração } \\
\left(2 \mathrm{DC}, l^{-1}\right)\end{array}$ & 3,0 & 157,9 & 94,5 & 168,4 & 113,0 \\
\hline $\begin{array}{l}\text { Concentração Máxima } \\
\left(2 \mathrm{DC}, l^{-1}\right)\end{array}$ & 12,8 & 310,5 & 173,2 & 273,8 & 195,9 \\
\hline Diâmetro médio (2DC, $\square \mathrm{m}$ ) & 160 & 239 & 213 & 244 & 253 \\
\hline $\begin{array}{l}\text { Média da Concentração } \\
\left(1 \mathrm{DP}, l^{-1}\right)\end{array}$ & 0,4 & 23,7 & 4,2 & 23,6 & 21,7 \\
\hline $\begin{array}{l}\text { Concentração Máxima } \\
\left(1 \mathrm{DP}, l^{-1}\right)\end{array}$ & 1,9 & 55,4 & 21,8 & 48,6 & 47,3 \\
\hline Diâmetro médio (1DP, $\square \mathrm{m}$ ) & 794 & 612 & 656 & 663 & 640 \\
\hline
\end{tabular}

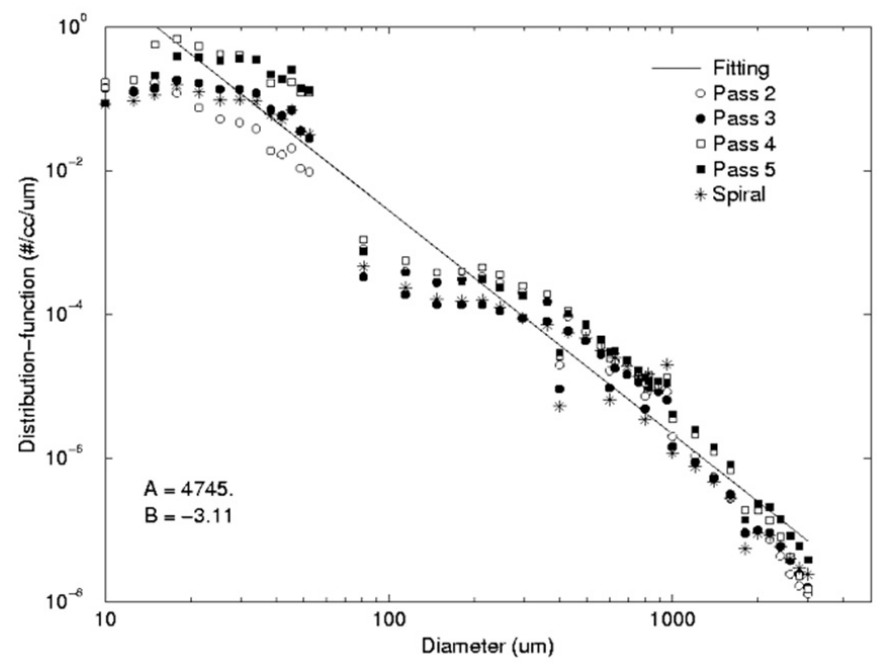

Figura 13 - Função Distribuição de hidrometeoros para as passagens 2 (círculos branco), 3 (círculos pretos), 4 (quadrados pretos), 5 (quadrados brancos) e espiral descendente (estrelas). Os coeficientes de regressão linear indicados são para o dia 10 de fevereiro de 1999.

obtido para o expoente $b$ se aproxima daquele encontrado por Auer (1972) para a distribuição de graupel em tempestades nos Estados Unidos, mas que o valor do coeficiente linear é cerca de uma ordem de magnitude maior para o caso presente. Ajustes a outras funções-distribuição podem, evidentemente, ser testados.

\section{CONCLUSÕES}

Modelos de previsão de tempo e clima apresentam incertezas significativas no tratamento da convecção profunda, em virtude do pouco conhecimento disponível acerca da microestrutura de nuvens, especialmente no que se refere à fase de gelo. Isto impõe limites sérios na representação da convecção nos trópicos e sua interação com a grande escala, bem como na quantificação do impacto do efeito indireto dos aerossóis em cenários de mudanças climáticas.

O sistema convectivo da Amazônia analisado neste artigo mostra elevadas concentrações de partículas em todos os níveis, especialmente no interior dos núcleos adiabáticos. Concentrações medidas pela FSSP foram da ordem de centenas por centímetro cúbico e, pela $2 \mathrm{DC}$, de várias centenas de partículas por litro. $\mathrm{O}$ ambiente da nuvem era propício para a ativação de mecanismos do tipo multiplicação de gelo por encrostamento-fragmentação ("riming-splintering", Hallet e Mossop, 1974) e para a ativação de muitos núcleos de gelo devido às elevadas supersaturações com respeito ao gelo (compatíveis com ascendentes intensos). Também existia a possibilidade de quebra de cristais como rosetas e dendritos. Ainda assim, como a nuvem apresentava topo com temperaturas abaixo da mínima observada pela aeronave (já próxima aos -40 
${ }^{\circ} \mathrm{C}$ ), acredita-se que a nucleação homogênea do gelo a partir das gotículas liquidas tenha sido o principal fator para produção de grandes concentrações de partículas.

Uma grande variedade de formas de cristais de gelo foi encontrada, incluindo combinações de hábitos primários sobrepostos. Nas primeiras penetrações da aeronave instrumentada no interior do sistema de nuvens, foi verificada uma concordância entre o hábito primário dominante e a temperatura do ambiente (que é um fator determinante para o crescimento do cristal de gelo ao longo de um ou outro eixo). Nas passagens finais da aeronave, tal relação mostrou-se mais fraca, sugerindo que, à medida em que o sistema amadurecia e tendia à fase de dissipação, o transporte de cristais pelas correntes no seu interior e a sedimentação desses cristais levassem ao aparecimento de partículas com formas diferentes daquelas esperadas em função apenas da temperatura. A superposição de hábitos também sugere que é comum que cristais de gelo passem por mais de um processo de crescimento no interior de nuvens convectivas tropicais.

Contrastando com a diversidade de formas de cristais, as concentrações máximas em cada passagem foram bastante uniformes, assim como as distribuições por tamanho. Isto sugere ser possível usar representações relativamente simples para representar essas variáveis em modelos atmosféricos com convecção explícita.

\section{REFERÊNCIAS BIBLIOGRÁFICAS}

ADAMS, D. K., SOUZA, E. P., COSTA, A. A. Convecção Úmida na Amazônia: Implicações para Modelagem Numérica. Revista Brasileira de Meteorologia, v.24, p. 168-178, 2009

ANDREAE, M. O., D. ROSENFELD, P. ARTAXO, A. A. COSTA, G. P. FRANK, K. M. LONGO, M. A. F. SILVADIAS: Smoking rain clouds over the Amazon. Science, 303, 1337-1342, 2004.

ARTAXO, P., E. P. FERNANDES, J. V. MARTINS, M. A. YAMASOE, P. V. HOBBS, W. MAENHAUT, K. M. LONGO, A. CASTANHO. Large-scale aerosol source apportionment in Amazonia. Journal of Geophysical Research-Atmospheres, v. 103, p. 31837-31847, 1998.

ARTAXO, P., MARTINS, J. V., YAMASOE, M. A., PROCOPIO, A. S., PAULIQUEVIS, T. M., ANDREAE, M. O., GUYON, P., GATTI, L. V., AND LEAL, A. M. C.: Physical and chemical properties of aerosols in the wet and dry seasons in Rondonia, Amazonia, Journal of Geophysical ResearchAtmospheres, v. 107, p. 8081, 2002.

AUER, A. H. Distribution of graupel and hail with size. Monthly Weather Review, v. 100, p. 325-328, 1972.

BAKER, M. B., PETER, T.: Small-scale cloud processes and climate. Nature, v. 451, p. 299-300, 2008.
BAUMGARDNER, D., STRAPP, W., DYE, J. E. Evaluation of the Forward Scattering Spectrometer Probe. Part II: Corrections for Coincidence and Dead-Time Losses. Journal of Oceanic and Atmospheric Technology, v. 2., p. 626-632, 1985.

CHEN, J.-P., G. M. MCFARQUHAR, A. J. HEYMSFIELD, V. RAMANATHAN. A modeling and observational study of the detailed microphysical structure of tropical cirrus anvils, Journal of Geophysical Research-Atmospheres, v. 102, p. 6637-6653 1997.

CONNOLLY, P. J., ET AL. Calibration of the Cloud Particle Imager Probes Using Calibration Beads and Ice Crystal Analogs: The Depth of Field. Journal of Oceanic and Atmospheric Technology, v. 24, p. 1860-1879, 2007.

COSTA, A. A., C. J. DE OLIVEIRA, J.C.P. DE OLIVEIRA, A. J. C. SAMPAIO. Microphysical Observations of Warm Cumulus Clouds in Ceará, Brazil. Atmospheric Research, v. 54, p. 167-199, 2000.

COSTA, A. A., T. PAULIQUEVIS. Aerossóis, nuvens e clima: aspectos resultados do experimento LBA para o estudo de aerossóis e microfísica de nuvens. Revista Brasileira de Meteorologia, v. 24, p. 234-253, 2009.

DYE, J. E., BAUMGARDNER, D. Evaluation of the Forward Scattering Spectrometer Probe. Part I: Electronic and Optical Studies. Journal of Oceanic and Atmospheric Technology, v. 1., p. 329-344, 1984.

FERRIER, B. S.,: A double-moment multiple-phase fourclass bulk ice scheme. Part I: Description. Journal of The Atmospheric Sciences, v.51, p. 249-280, 1994.

FORSTER, P., V. RAMASWAMY, P. ARTAXO, T. BERNTSEN, R. BETTS, D.W. FAHEY, J. HAYWOOD, J. LEAN, D.C. LOWE, G. MYHRE, J. NGANGA, R. PRINN, G. RAGA, M. SCHULZ AND R. VAN DORLAND. Changes in Atmospheric Constituents and in Radiative Forcing. In: Climate Change 2007: The Physical Science Basis. Contribution of Working Group I to the Fourth Assessment Report of the Intergovernmental Panel on Climate Change, Cambridge University Press, Cambridge, United Kingdom and New York, NY, USA, 2007.

FREUD, E., ROSENFELD, D., ANDREAE, M. O., COSTA, A. A., ARTAXO, P. Robust relations between $\mathrm{CCN}$ and the vertical evolution of cloud drop size distribution in deep convective clouds. Atmospheric Chemistry and Physics, v. 8, p. 1661-1675, 2008.

HALLETT, J., S. C. MOSSOP, 1974. Production of secondary ice particles during the riming process. Nature, v. 249, p. 26-28, 1974.

HEYMSFIELD, A. J., BAUMGARDNER, D. Summary of a work- shop on processing 2D probe data. Bulletin of the American Meteorological Society, v. 66, p. 437-440, 1985. 
HEYMSFIELD, A. J., A. BANSEMER, P. R. FIELD, S. L. DURDEN, J. L. STITH, J. E. DYE, W. HALL, C. A. GRAINGER. Observations and parameterizations of particle size distributions in deep tropical cirrus and stratiform precipitating clouds: Results from in situ observations in TRMM field campaigns. Journal of the Atmospheric Sciences, v. 59, p. 3457-3491, 2002.

KAUFMAN, Y. J., P. V. HOBBS, V. W. J. H. KIRCHOFF, P. ARTAXO, L. A. REMER, B. N HOLBEN, M. D. KING, D. E. WARD, E. M. PRINCE, K. M. LONGO, L. F. MATTOS, C.A. NOBRE, J. D. SPINHIRNE, Q. JI, A. M. THOMPSON, J. F. GLASON, S. A. CHRISTOPHER, S. C. TSAY. Smoke, clouds and radiation - Brazil (SCAR-B) experiment. Journal of Geophysical Research-Atmospheres, v. 103, p. 31783-31808, 1998.

KNOLLENBERG, R. G. The optical array: An alternative to scattering or extinction for airborne particle size determination. Journal of Applied Meteorology, v. 9, p. 86-103, 1970.

KNOLlenBERG, R. G., K. KELLY, J. C. WILSON. Measurements of high number densities of ice crystals in the tops of tropical cumulonimbus. Journal of Geophysical Research-Atmospheres, v. 98, 8639-8664, 1993.

KOROLEV, A. V., KUZNETSOV, S. V. , MAKAROV, YU. E., NOVIKOV, V. S. Evaluation of measurements of particle size and sample area from optical array probes. Journal of Atmospheric and Oceanic Technology, v. 8, p. 514 $-522,1991$.

LAWSON, R. P., CORMACK, R. H.L WEAVER, K. A. A new airborne precipitation spectrometer for atmospheric research. PREPRINTS, EIGHTH SYMPOSIUM ON METEOROLOGICAL OBSERVATIONS AND Instrumentation, Anaheim, CA, American Meteorological Society, p. 30-35, 1993.

LIU, Y., Y.YOU, W.YANG, F. LIU. On the size distribution of cloud droplets. Atmospheric Research, v. 35, p. 201-216, 1995.

LIU, Y., P. H; MCGRAW, RL; M. A. MILLER, S. NIU. Theoretical expression for the autoconversion rate of the cloud droplet number concentration, Geophysical Research Letters v. 34, L16821, doi:10.1029/2007GL030389, 2007. MARTINS, J A; GONÇALVES, FÁBIO LUIZ T.; MORALES, CARLOS A.; FISCH, GILBERTO F.; PINHEIRO, FRANCISCO GERALDO M.; LEAL JÚNIOR, JOÃO BOSCO V.; OLIVEIRA, CARLOS J.; SILVA, EMERSON M.; OLIVEIRA, JOSÉ CARLOS P.; COSTA, ALEXANDRE A.; SILVA DIAS, MARIA ASSUNÇÃO F. Cloud condensation nuclei from biomass burning during the Amazonian dry-to-wet transition season. Meteorology and Atmospheric Physics, v. 104, p. 83-93, 2009.
MEYERS, M.P., R.L. WALKO, J.Y. HARRINGTON, W.R. COTTON: New RAMS cloud microphysics prameterization. Part II: The two-moment scheme. Atmospheric Research, v. 45, p. 3-39, 1997.

PINNICK, R., G., GARVEY, D. M., DUNCAN, L. D. Calibration of Knollenberg FSSP light-scattering counters for measurement of cloud droplets. Journal of Applied Meterorology, v. 20, p. 1049-1057, 1981.

ROSENFELD, D. TRMM observed first direct evidence of smoke from forest fires inhibiting rainfall. Geophysical Research Letters, v. 26, p. 3105-3108, 1999.

SHERWOOD, S. C. Aerosols and ice particle size in tropical cumulonimbus. Journal of Climate, v. 15, p. 1051-1063, 2002.

STITH J. L., J. E. DYE, A. BANSEMER, A. J. HEYMSFIELD, C. A. GRAINGER, W. A. PETERSEN, R. CIFELli: Microphysical observations of tropical clouds. Journal of Applied Meteorology, v. 41, p. 97-117, 2002.

TAKAHASHI, T., K. SUZULI, M. ORITA, M. TOKUNO, R. DE LA MAR. Videosonde observations of precipitation processes in equatorial cloud clusters. Journal of The Meteorological Society Of Japan., v. 73, p. 509-534, 1995.

UNALOWSKY, Z., CONNOLLY, P. J., ET AL. Using ice crystal analogues to validate cloud ice parameter retrievals from the CPI ice spec-trometer data. Proceedings of the 14th Int. Conf. on Clouds and Precipi- tation, Bologna, Italy, International Commission on Clouds and Precipitation, p. 1175-1178, 2004.

WALKO, R. L, COTTON, W. R., HARRINGTON, J. L., MEYERS, M. P. New RAMS cloud microphysics parameterization Part I: the single-moment cheme. Atmospheric Research, v. 38, n. 1, p. 29-62, 1995.

XIE, X. L., XD. Analytical three-moment autoconversion parameterization based on generalized gamma distribution. Journal of Geophysical Research-Atmospheres v. 114, 2009. 